\title{
How Jordanian University Students Perceive the Opportunities and Challenges of Using Facebook as a Supplementary Learning Resource?
}

\author{
http://dx.doi.org/10.3991/ijet.v10i1.4265 \\ Y. M. Arouri \\ Tafila Technical University, Tafial, Jordan
}

\begin{abstract}
This study aimed at investigating Jordanian university students' opinions of utilizing a Facebook application that is linked to a university course. This coursespecific 'Facebook page' that is entitled "Our Environment is Our Responsibility" was created specifically as an additional course material to learn more how university students who enrolled in this course perceive this resource as a new learning tool. Two questionnaires were distributed to 64 students. The first questionnaire was implemented at the beginning of the semester. It consisted of open-ended questions to learn about students' proposed expectations of utilizing this new platform. The other questionnaire was given at the end of the semester to learn more about students' perceptions of this new experience. Findings of this study revealed that the majority of students perceived Facebook as an attractive, valuable and accepted learning resource. However, the students faced many obstacles that hindered the ultimate benefit of utilizing this supplementary online learning resource. Recommendations and further research opportunities regarding using Facebook as a learning tool are discussed.
\end{abstract}

Index Terms-Social Network Site, Facebook, university students, supplementary online learning resource, Jordan, opportunities and challenges.

\section{INTRODUCTION}

Nowadays students are more open to social media websites. The new Social Network Sites (SNSs) such as Blogger, Google Plus, Twitter, Facebook, and MySpace have increased and become the most popular sites in current years. These sites are considered as web-based services and platforms in which users could create social networks and relations among other users such as friends, colleagues, and relatives. Using SNSs would enable users to build public and private profiles and share links, ideas, pictures, posts, interests, activities, and events with people who are part of their extended social networks [20], [4].

Facebook is one of these online forums that are well received and used by many users. It has a clear impact on the youth personal development throughout the world. According to eBizMBA [10] the most popular social networking site in the world is Facebook which was created in 2004 by a group of students from Harvard University [6]. This site is similar to the other SNSs that empowers users to communicate and interact with other users to share photos, links, videos, comments, messages, and knowledge to make the world more open and connected [30]. Aydin [3] pointed out that Facebook is a social networking and an online site that "presents a platform used by individuals; it focuses on building and reflecting social relations in accordance with interests and/or activities" (p. 1094). In addition to all of these features that are common in most SNSs, Facebook "offers a variety of additional functions, including online games, virtual farms, virtual pets, the wall, and virtual gifts" [16, p. 304). In 2013, the number of the active users, who was using Facebook for communications and socializations with others all over the world, reached more than 1.28 billion [11]. However, the number of Facebook fans in Jordan was more than three million: $59 \%$ of local users are males and $41 \%$ are females [33]. In addition, socialbakers [33] indicated that the largest age group range that used Facebook in Jordan was (18-24) year olds, with a percentage of $40 \%$, followed by the (25-34) age group with a percentage of $30 \%$.

The related research findings indicated that Facebook was created primarily for social networking activities and interactions. According to Pempek et al. [23] "Facebook was used most often for social interaction, primarily with friends with whom the students had a pre-established relationship offline" [p. 227]. Similarly to Pempek et al. [23], McCarthy [20] asserted that Facebook is used as a global social networking website, and has not been extensively used for educational purposes. Although Facebook served as an online social context, it has been rapidly considered as a respectable e-learning environment in the educational field. Wong et al. [37] asserted that online SNSs such as Facebook help students to increase learning and engage them into the academic and social sittings. According to Souleles [34] Facebook is popular and very accepted among the wider student population. For instance, socialbakers [33] estimated that the ages of $40 \%$ of Facebook users, in Jordan, are between 18-24 years. That is, most of Facebook users are undergraduate students who still pursue their undergraduate degrees. In an international research study, Wong et al. [37] found that $90 \%$ of college students use Facebook. In United States of America, more than $80 \%$ of United States college students use Facebook [5]. In addition, Junco [17] pointed out that $97 \%$ of USA university students used Facebook. At the University of South Australia, up to $90 \%$ of university students were active users of Facebook [36]. Oradini and Saunders [22] reported that Facebook is well-known and accepted among students generation. In sum, Facebook has a clear impact on university campuses [28]. This indicated that Facebook is very important to university students; it is part of their daily life, and it is too big to be ignored. Ryan et al. [27] declared that Facebook consider as the most popular SNSs and the fastest growing among 
university students. Hanson et al. [12] demonstrated that college students spend the greatest amount of their personal time communicating by using SNSs.

Given discussion pointed out the necessity of viewing the SNSs differently to maximize the outcomes of these websites in the educational field. As a result, this study focuses on Jordanian students in the institutions of higher education and investigates their viewpoints of implementing such SNSs as learning additional resources. The following paragraphs will discuss the research problem and main questions.

\section{RESEARCH PROBlEM AND QUESTIONS}

Previous literature indicated that Facebook is the most popular social networking site. Furthermore, it is very accepted among the wider student population and the fastest growing among university students [34], [37], [28], [27]. Similarly in Jordan, socialbakers [33] reported that the majority of Facebook fans are university students. However, based on my experiences as a college instructor for several years, the Jordanian students use Facebook features for non educational purposes; they mainly use it for personal and social interactions and communications. Although Facebook is emerging as a newly recognized educational platform, the higher education institutions did not utilize it as a formal accepted learning resource. As a result, this study aimed at investigating the potential of implementing Facebook as an educational resource. This is one of the main motives of this study. Given discussion empowered the researcher of this study to explore university students' viewpoints of using Facebook a supplementary course resource in one of the Jordanian universities. Specifically, this research intended to investigate students' expectations and perceptions of the opportunities and challenges of using Facebook as an additional learning resource. The main research questions are:

1. What are university students' expectations of utilizing Facebook as an educational resource?

2. How do university students' perceive the advantages of utilizing Facebook as a supplementary educational resource?

3. How do university students' perceive the obstacles of utilizing Facebook as a supplementary educational resource?

\section{RESEARCH PROCEDURAL DEFINITIONS}

For the purposes of this research, the following are the definitions of the research main concepts:

Facebook is one of the social networking and an online site that empowers users to communicate and interact online with other users to share photos, links, videos, comments, messages, and knowledge. For the purposes of this study, the use of Facebook is optional and it is implemented as a supplementary learning resource.

University students are undergraduate students in the Faculty of Educational Sciences who are enrolled in one of the courses that utilized Facebook as a supplementary course resource. For the purpose of this research, the participants' specializations are: classroom teacher, and early childhood education.

Opportunities are the perceived benefits of utilizing Facebook as a supplementary learning resource.
Challenges are difficulties or problems faced by students during using Facebook as a supplementary learning resource which may prevent or weaken the implementation of Facebook effectively

\section{RESEARCH IMPORTANCE}

On a global scale, there has been a serious lack of research on utilizing Facebook as an educational platform [3], [14], [25], [13], [34]. Likewise, there has been a lack of research that addressed Facebook use and role in Jordanian higher education institutions. For instance, despite the fact that Jordan has over 3 million active Facebook users [33]; there is a limited research and too few data which investigated utilizing Facebook as an educational resource in the Jordanian universities contexts. Therefore, it is significant to conduct a research study to learn more about the experiences of the Jordanian university students before and after utilizing Facebook as an educational environment. Investigating the Jordanian university students' viewpoints can provide higher education institutions stakeholders with a deeper understanding of building a more successful and collaborative educational environment that may enhance students' learning and development. In addition, Jordanian student's voices and perceptions regarding the use of Facebook as a learning resource should be heard to create an effective educational context. Consequently, the potential of Facebook in promoting collaborative and cooperative learning should be evaluated in Jordanian higher education contexts. Internationally several studies [3], [14], [13], [25], [32] were conducted to understand the abilities of Facebook for enhancing students' levels of engagement in learning. So, this issue warrants an investigation in Jordan because there is a limited published research on the subject.

\section{THEORETICAL FrAMEWORK}

This study drew on the tenets of the theory of student involvement [2], [35], [38], [14]. Involvement concept overlaps with other related concepts such as "integration" and "engagement" [2]. The theory of student involvement discusses that "a particular curriculum, to achieve the effects intended, must elicit sufficient student effort and investment of energy to bring about the desired learning and development [2, p. 522]. That is, the theory of involvement does not involve learners in an inactive role as recipients of information, but it asserts that learners in the learning process should be active participants [2]. In addition, this theory asserted that the educators have a vital role in the involvement environment. They are encouraged to "focus less on what they do and more on what the student does: how motivated the student is and how much time and energy the student devotes to the learning process" [2, p. 522]. This means course content, teaching techniques, and other resources should be used by teachers to engage students in learning and development processes [2]. According to Taylor and Parsons [35] the role of educators is to continue seeking and applying educational approaches that empower student involvement in learning in and out the boundaries of classroom. In addition, it is important to improve learner's involvement. So, the instructor not only needs to assist him/her to learn but also to reinforce his/her ability to learn how to learn and to become lifelong student in a knowledge-based society [35]. 
Astin [2] addressed that student involvement refers to "the amount of physical and psychological energy that the student devotes to the academic experience" [p. 518]. Based on his perspective, involved student is the one who "devotes considerable energy to studying, spends much time on campus, participates actively in student organizations, and interacts frequently with faculty members and other students" [p. 518]. Kuh stated that involvement, today, refers to "the amount of time and effort that students spend on educational activities that are related to college academic work [As cited in [16], p.304]. Student involvement has emphasized upon "increasing achievement, positive behaviors, and a sense of belonging in students so they might remain in school" [35, p. 4]. Zepke et al. [38] pointed out that there are several factors that play significant roles in student involvement. These factors include: "student motivation, teacher-student interactions, learners interacting with each other, the role of institutional policies, sociopolitical factors and the role of non-institutional influences such as family, friends, health and employment" [p. 2]. With same sense, Roberts and McNeese [26] explained variety of steps that encourage students to become more engaged and involved in college campuses: Student-peer interaction, social integration, service learning, promoting diversity, participating in athletics and extracurricular activities.

Students have changed over the last three decades. The current digital generation experience life differently compared with the parents and grandfathers. Today's students engage within a technology rich society. So, schools should respond to their needs and access to the key of their success. Pedagogy, curriculum, and assessment strategies should be aligned with students' abilities, goals, expectations, and needs. Teachers need to better understand the needs and interests of the digital generation to decide what possibilities are required to engage them in the educational system effectively. According to Prensky "Today's world requires collaborative critical thinkers, creative and courageous innovators, and true lifelong learners" [As cited in [35], p. 7].

Scholarly studies of Facebook [16], [30], [27], [7], [14] revealed a significant relationship and a positive correlation between the use of social networking sites, specifically Facebook, and student involvement. Jenny et al. [16] stated that the use of Facebook motivates learners to learn, creates an effective learning and classroom climate, and enhance teacher-student relationships. With the same line of thought, Zepke et al. [38] asserted that the Facebook has the potential to empower students to be active learning agents, who are able to achieve their goals, and to construct their own knowledge.

In sum, the idea of exploring this research emerged from the tenets of student involvement theory [2], [35]. Such tenets were utilized to understand and investigate students' expectations and viewpoints of the opportunities and the challenges of utilizing Facebook as a supplementary learning resource.

\section{LITERATURE REVIEW}

Many studies were conducted to detect the role of Facebook as an educational resource. For example, in a study that was conducted by Crews and Stitt-Gohdes [9], the authors used a Facebook application as a method to involve business communication students, at University of South Carolina and University of Georgia, USA, in writ- ing for real-world in order to accomplish the class activities. During the service-learning project, business communication students were asked to create communication documents to improve the nonprofit's communication with the public. To accomplish this intent, they implemented several social networking sites such as Facbook. The authors demonstrated that implementing social networking sites into the classroom activities assisted students to "write more concisely and think critically about the key elements of writing and of the nonprofit's mission" [9, p. 77].

Another study was conducted by Irwin et al. [13] at Griffith University, Australia, to explore how individual Facebook pages would be able to facilitate learning activities at university level. The participants of the study developed individual Facebook pages to share information relevant to the courses that they were taking and giving them the opportunities to interact with each other. The authors created two questionnaires, one at the beginning of the semester and the other one at the end of the semester. The first questionnaire showed that nearly all students have an active Facebook account. In addition, it indicated that the majority of students expected that a Facebook page would allow them to share course information and increase their interaction with themselves and their instructors. The second questionnaire indicated that most students engaged with the course Facebook page at some stage.

In their study, at Cape Peninsula University of Technology, South Africa, Ivala and Gachago [14] investigated the potential of social network sites such as Facebook and blogs in enhancing students' levels of engagement in learning. The findings of the research asserted that social network sites such as Facebook and blogs have a potential in enhancing university students' engagement in learning both on-campus and off-campus. So, the article recommended utilizing these technologies in higher education institutions to enhance student's interaction and engagement in learning process which lead to promote students' performance and their retention.

On the other hand, several studies spotted the effects of implementing Facebook on students' achievement, engagement, and satisfaction. For example, a quantitative study, at National Formosa University, Taiwan, that was conducted by Jenny et al. [16] to compare the effectiveness of different learning environments on undergraduate students who use Facebook application as instructional method and who do not use it in their learning process. This research measured two dimensions: student grades and learning engagement. It was used a pretest-posttest control group experimental design. The experimental group received the interactive Facebook instructional method. Whereas the control group students received the non-Facebook instructional method. The findings revealed that experimental group had a significant positive effect on grades and engagement. The authors asserted that it is possible to use social network sites as educational communication and interaction tools to allow university instructors to play a more active and participatory role.

In addition to the previous review of literature that highlighted the impact of Facebook on face-to-face classes, the previous literature detected the impact of Facebook as a learning resource on online courses. In this regard, Miller [21] conducted a comparison study at Sam Houston State University in USA, to investigate the im- 
pact of the use of Facebook as an online discussion tool on students' participation and response time. The study showed that students participated more quickly more frequently to the articles posted for discussion when they used Facebook for their online discussions. In addition, Facebook can be an effective tool for promoting a sense of social presence and perceiving a greater sense of learning, when students are familiar with the use of this medium. With the same line of thought, Shih [31] used a mixed method consisting qualitative and quantitative approaches to investigate the effect of integrating blended learning with Facebook and peer assessment for English for Business Communication course for college students at a technological university in Taiwan. The findings of this study indicated that students' learning motivation, interest, and interactions were enhanced when they integrated Facebook and peer assessment. Incorporating Facebook enabled learners to exchange information and share knowledge with classmates in a virtual community. This action empowered students to feel very confident when they interact in learning community. Finally, instructors should have extra efforts to consider grading, correcting, and guiding students' activities and assignments because the time is very consuming in this type of blended teaching and learning.

In the field of education, Facebook implementations were investigated. As an example, Shaltry et al. [29] illustrated the effect of using social media such as facebook on an elective course designed specifically for undergraduate students in pre-service teacher education program at Michigan State University in USA. The results indicated that these social tools such as Facebook would help preservice teachers to integrate technologies in way that will benefit their future students, classmates, and the better education community.

Although Facebook impact was investigated thoroughly as presented in the previous discussion of literature, limited research has been conducted on university students in Arabic countries. One of these studies was conducted by Khadr [18]. The aim of the study was to understand why Egyptian youth use Facebook. In her study, she investigated the nature of social relationships and friendships formed by Egyptian youth. Further, she aimed to monitor and analyze the social and psychological (positive and negative) effects throughout using Facebook. The sample of this study included 136 Facebook users from students of Egyptian universities: Cairo University and the British University. The study found that the majority of study sample used Facebook for entertainment goals, while the minority considered Facebook as a tool to create new friendships, and to communicate with others and develop social relationships.

Another study was conducted in Jordan. In her study, Jarar [15] aimed to find out nature of participating in Facebook and its relationship to the trends of Jordanian young people about family relationships. The researcher used the descriptive method and a questionnaire to collect the research data. The results showed that the percentage of young Jordanians who have a Facebook account reach $(74.4 \%)$ of the total Jordanian youth. The ratio of male participants in the site is $(56 \%)$, while the female participants are $(44 \%)$. It also found that nearly $(73.8 \%)$ of the participants visited the Facebook site daily. Further, more than half of the young, who used Facebook, believed that their participation reduced the time they spend with their families, and $(45.6 \%)$ of the participants pointed out that their participation in the site impacted their lives positive$1 y$.

As a conclusion, the previous literature addressed the international interest in investigating the Facebook impact as an educational resource on university students, specially, in the undergraduate level. The previous literature detected the consequences of this SNS on different educational contexts. However, there is paucity in studies that investigated the effects of Facebook as an educational resource on Jordanian higher educational institutions. Thus, this study aimed at bridging the gap by providing more information about the potential of using Facbook as a supplementary learning resource in undergraduate level.

\section{RESEARCH METHODS}

To answer the research main questions, the researcher collected data from the students who were enrolled in one of the courses at the Faculty of Educational Sciences at the University of Jordan. The researcher created two questionnaires: the initial questionnaire was implemented at the beginning of the semester. The other questionnaire was given at the end of the semester. Each questionnaire consisted of number of open ended questions as well as some demographic information. A detailed description of the data collection methods is presented in the following paragraphs.

\section{A. Participants}

The study was conducted at the Faculty of Educational Sciences at the University of Jordan during the second teaching semester of the academic year 2013/2014. The study sample consisted of all of the students $(n=64)$ who were registered in a course entitled Environmental Education for the Child. They were 19 freshman students, 24 sophomore students, 11 junior students, and 10 senior students. The students' specializations were: Classroom Teachers (CT) and Early Childhood Education majors (ECE).

An open discussion with the students regarding their expectations of the course was conducted at the beginning of the semester. Based on that discussion, a Facebook page was created as an additional learning resource in Environmental Education for the Child course. Due to some cultural and personal restricts, the students were informed that participation in this Facebook page is voluntary but strongly encouraged for students who have access to the Facebook page. The students' access to the Facebook page was supervised by the instructor of the course to make sure that the discussed content is related to the course objectives and to check the readability of the presented content and insights.

At the beginning of the semester all of the students were asked to respond to a questionnaire that has two sections. The first section included demographic information such as: student's name, age, specific specialization, academic year, and whether they have a Facebook account or not. The second section of the questionnaire included three open-ended questions to investigate their expectations regarding using a Facebook page as one of the learning resources in the Environmental Education for Child course that they are registered in. 


\section{B. Data Analysis}

All of the returned questionnaires were read and re-read precisely. Data analysis of the open-ended questions focused on the identification of the most repeated themes and issues emerging from presented responses. According to Creswell [8] analyzing the data in qualitative research is a process that consists of many steps that aimed at "reducing the data into themes through a process of coding and condensing the codes, and finally representing the data in figures, tables, or a discussion" [p.148]. The analytical phase of this qualitative research followed the systematic approach to analysis [8]. Specifically, the researcher coded the participants' answers in the open ended questionnaires' questions. To do so, the data were read and re-read to reduce it in fewer segments and codes. After that the codes were combined based on the common relationships among them to create the main themes.

\section{Trustworthiness}

According to Lincoln and Guba [19] in order to enhance the trustworthiness of the qualitative study the researcher should be aware of credibility, transferability, dependability, and conformability. To do so, the researcher read carefully each response of the participants with respect to the information they provided in the initial questionnaire, their culture, values, and beliefs. In addition, provided a detailed description of the research process, so the readers can understand the context of this research and decide to what extent the findings of this research can benefit them in other contexts.

\section{FINDINGS AND DISCUSSION}

\section{A. Expectations of Utilizing Facebook as a Learning Resource}

The first question of this research was: What are the students' expectations of utilizing Facebook as an educational learning resource? To answer the question, an initial questionnaire that consisted of 3 open ended questions was distributed to the students to learn more about their prospective thoughts of utilizing Facebook as a learning resource associated with courses. The students' insights were varied. Based on the initial questionnaire responses there were 37 out of 64 students who had Facebook accounts before taking this course.

Many of the students $(n=26)$ mentioned that using a Facebook page as a course material will benefit them in providing new knowledge. The students pointed out that environmental education issues discussed in this offered course need advanced knowledge. So, this new way of virtual learning platform can help in this. The majority of the students who mentioned this benefit were sophomore students.

Some students were more detailed in their responses and mentioned that Facebook has many advantages that encourage them to participate. One of the students stated: "I think the provided knowledge that I will gain from Facebook is better and more advanced than the knowledge from a textbook. Further, in this Facebook page I expect a variety of viewpoints and more critical insights." (Sophomore, ECE).

Another student, who did not have a Facebook account before taking the course, provided similar expectations. She stated:
I think using the Facebook page will expand the learning objectives. We will know more from this course because it should not be isolated from our daily life and it should discuss the relationship between human beings and their environment I think using Facebook page will add to this course (Sophomore, CT).

Interestingly, eleven out of 60 participants believe that the Facebook Page will be beneficial in searching for knowledge although they do not have a Facebook account. This result reflects the impact of Facebook for both the users and other students who may not have access to Facebook. The limited access to Facebook will be explored in the section that discusses the challenges of implementing Facebook as a learning resource.

Although the majority of the students were supportive of the new idea of using a Facebook page as a learning resource, some of the students did not expect that this page can benefit them $(n=8)$. One of the students stated: "I do not think the Facebook page will support the course because there are many websites that discuss environmental issues" (Sophomore, ECE). Another student commented: "I think using a course Facebook page will be a good idea. However, I think that if I need to get information I will search through specialized websites. I am not sure about the benefit that I may get from using this page" (Sophomore, ECE).

Many of the students who did not support this idea did not have a Facebook account at the beginning of the semester mentioned. As example of their thoughts, one of the students said:

"I do not have a Facebook account. I do not think that I may benefit from this page. I can search through the internet and find the information that I need" (Senior, CT).

One reason of this result could be related to the limited knowledge of Facebook possibilities from the students who did not have Facebook accounts prior to this course.

\section{B. Students' Expectations and Viewpoints of the Facebook Page Content}

The second question of the initial questionnaire at the beginning of the semester focused on the students proposed thoughts of the expected published content. The participants expected many topics that may be included in the content of the Facebook page. The majority of them anticipated that this page may include: Guidelines of protecting environmental resources, environmental news, renewable resources, environmental problems and solutions, and countries' achievements regarding environmental domain. This content can be presented through: pictures, Videos, articles, poetry, and caricature. One of the students stated: "The Facebook Page may include environmental terms, natural environment pictures, a comparison between different environments, and environmental activities and projects" (Freshman, ECE).

Some of the students expected that this page will serve as an arena for environmental thoughts exchange among the students. One of the participants stated:

It will benefit us in knowing more about the environment. Through this page, students will be able to know important things about the environment; communicate with each other, and exchange ideas about clean environment and the best use of environmental resources. So, people can become more aware of the environment (Freshman, CT). 
The students, who use Facebook daily, showed confidence in their expectations of the benefits of the Facebook page. One of them stated:

Sure, this page will strongly support the course because I know many of my colleagues who use Facebook continuously. We believe this page will spread the word quickly to the university students and other people who may have the same interest, we can participate our thoughts even if we miss the Face-to-face class (Sophomore, ECE).

The students' responses focused on the Facebook page content and did not reflect any sign of social communication and its effect on the acquisition of the course content.

\section{Students' Perceptions at the End of the Course}

In the last week of the semester, the participants responded to another questionnaire. The purpose of this questionnaire was to learn more about students' viewpoints after utilizing Facebook as a supplementary course resource. The open-ended questions in this questionnaire focused on the students' perceptions of using the Facebook page during the semester.

By the end of the semester the number of the students who utilized the course Facebook page increased and reached 54 students comparing to 37 students who already had a previous access to Facebook prior to the course. However, based on the participants' responses all of the users experienced Facebook as a supplementary course resource for the first time. This experience was a new opportunity to the students to vision Facebook uses differently. So, they provided many insights of this new educational experience. The following paragraphs discuss the main findings.

\section{Advantages of Utilizing Facebook as a Learning Resource}

As a response to the question: How do university students perceive the advantages of utilizing Facebook as an educational learning resource? The students pointed out that they were interested in sharing and reading additional updated information related to the environment course.

One of the students said:

Visiting this page was beneficial for me in many ways: I gained a new knowledge that was not offered in other social media websites. Specifically, I learned many creative ideas about recycling. I still remember that video about that woman who reproduced many nice items by recycling. I become more interested in reading more about environmental news (Senior, CT).

In addition, many students emphasized that new way of presenting the facts about the environment through posting pictures and videos was fruitful. These published materials increased the awareness of environmental issues. One of the students commented:

I had the opportunity to see many pictures and videos about environmental problems. Also, I noticed that many of these problems could be solved and handled... throughout the semester I reviewed many environmental problems that I did not know before, especially the environmental problems that face the world. This helped me search more and look for other related sites that discussed each problem deeply (Freshman, CT).

The mentioned insights draw the attention to the need to cope with the explosion of knowledge in this digital era. Although teaching methods are vital to handle this issue, social networking sites such as Facebook can play an assistive role. This result supports Shih's [31] insight that integrating Facebook allowed learners to exchange information and share knowledge with classmates in a virtual community.

Another benefit of using Facebook as a supplementary course resource from the perspective of many students was the opportunity to view the role of Facebook differently. One of the students said: "For me, I benefited from this course Facebook page. At least, it guided me to rethink about the other uses Facebook. I used to log in for having fun with my friends" (Freshman, ECE). Another student stated: "I've learned new and strange environmental facts and information. Some of them were really interesting. During participating in the course Facebook page, I felt that I am using my time wisely in a useful way instead of wasting my time in searching aimlessly through Facebook" (Sophomore, ECE).

Furthermore, the perceived advantages of the Facebook page motivated students to invite their friends who did not take the "Environmental Education for the Child" course to visit the page and benefit from the presented insights. One of the students said:

At the beginning of the semester and when I was informed about this Facebook page, I thought it would be a waste of my time. Then, I began to spread the word about this page and started my participation. It was the first time in my life to follow environmental issues and news about our own environment. I searched purposefully to submit new information about environmental topics. This activity increased my interest in this topic. I am aware of many related topics and I owe this knowledge to this page (Junior, CT).

The presented quotes show how the students' visualization of Facebook uses expanded. So, they started to disseminate information about this course Facebook page to other friends. This finding is similar to previous literature that highlighted the positive effect of social networking sites that can serve as educational tools [24].

As the students start to notice the impact of this Facebook page on their academic achievement, they recommended such idea for the coming courses. In this regard, one of the students said:

Prior to this course Facebook page I did not have any interest in environmental topics and related issues. But after creating this page I liked the presented topics. I was interested in following the news about environment. I posted many environmental comments and pictures. I read my colleagues' insights and benefited from the discussion. The page is attractive and I hope to use it in the future even after this course to keep in touch with updated environmental news (Sophomore, CT).

The above insights are similar to Irwin et al. [13] study results that revealed that Facebook page has the potential to promote collaborative and cooperative learning. Moreover, the majority of students recommended integrating Facebook into future university courses.

In addition to the mentioned positive impact of utilizing Facebook as a supplementary course resource, many students added that the Facebook page is an untraditional idea that catches students' attention and engages them in course activities. One of them stated: "Although we had many activities and materials in this course, the participation through the Facebook page was the most interesting 
activity to me. I know many students like the electronic materials. This online page was very attractive (Senior, CT).

Furthermore, the students became more aware of the Facebook impact on the educational context. One of the comments was: "This page played an important role in spreading the environmental awareness among students and their friends and families. It's a new culture about the beneficial use of Facebook as an educational tool in addition to be a social tool. It fixed many misconceptions that I had before taking this class" (Junior, ECE).

As a conclusion, there is a clear agreement among the students regarding the positive impact of Facebook on both the social and educational aspects. The students discussed how this virtual community gave them mutual feedback and fixed many of the misconceptions regarding environmental facts. This result concurs with Pimmer et al. [24] and Souleles [34] studies that concluded the promising role Facebook as an educational tool in the institutions of higher education.

\section{E. Challenges Encountered Implementing Facebook}

Although the majority of the students expressed their appreciation of utilizing Facebook as a supplementary educational resource, some of them presented many insights regarding the obstacles of this new educational experience.

\section{1) Weakness in Internet Access}

Many of the participants pointed out that they encountered difficulty in watching the posted pictures and videos due to the weak Internet connection. One of the reasons is the fact that students relied on their personal mobiles to visit the Facebook page. Related to this point, one of the students stated: "I could not open the Facebook page because I only have a phone access to download the page. Internet connection via my phone is very weak, so I could not see the pictures, videos, or some posted comments" (Junior, CT).

Further, some students mentioned that the difficulty of visiting the course Facebook page was due to the fact that they do not have internet connection at home, and if they have it the connection lasted for a limited time. One of the students commented: "I do not have an Internet access at home. This prevented me from participating regularly even at the university the Facebook is prohibited. In order to participate, I accessed via my friend's phone. Since our courses and breaks were different, I found a hardship in participating" (Junior, ECE).

These notes from the students are present a very critical point since the university should provide a sufficient support for the students to enable them to gain the benefits of this new idea. This finding supports Arouri's [1] findings that highlighted the difficulties that university students face when they access some social networking sites such as Facebook since some of these sites are prohibited. So, students are not allowed to use them. These results guide the policymakers at the institutions of higher education such as university administration to rethink about the benefits of these SNS in serving the educational context. The previous perspective of Facebook as a social site was altered globally and the new opportunities should be given to SNS and investigated before making a judgment of preventing such websites.

\section{2) The Difficulty in Managing Courses Requirements}

On the other hand, the students were motivated at the beginning of the semester. Then, when they started working on other courses assignments and exams, they mentioned that the level of participation reduced since this resource is a supplementary platform. One of the students stated: "At the beginning of the course I participated a lot. But my participation became less because of the other assignments that I need to take care of in other courses" (Freshman, ECE). Another student stated: "I do not have Internet access at home and at the university I do not have time due to my busy schedule" (Senior, CT).

These thoughts show the lack of time management skills among students who experienced Facebook page as a learning resource. Adequate training is required to help students manage their time and cope with courses' requirements. So, if the Facebook page is suggested as an online learning resource the students should be aware more of the needed time to accomplish this online activity.

\section{3) Lack of Computer Skills}

One of the main obstacles that the students face in dealing with Facebook page is the lack of computer skills. Many students mentioned that the reason of their paucity of participation in the Facebook page is due to the limited computer skills. Specifically, many students did not use a Facebook account prior to the environmental education course. For example, one of the students said:

At the beginning of the semester I was very upset because I did not have a Facebook account. I did not know how to reach to the Facebook specific page. Further, I did not have any idea how to comment on others' thoughts and how to download pictures and videos Then, I asked my friend to teach me how to use it and how to participate (Freshman, CT).

Another said: "I did not know how to deal with Facebook page. When I created a Facebook account I forgot the password. I know how to open it but I do not know how to participate well due to my limited computer skills" (Sophomore, ECE).

The presented insights showed the need of further training that accompanied offering the Facebook as a learning resource. Some students do not have this experience before, so a specified workshop or related training can maximize the outcomes of such new idea. There should be a way to rectify the weakness in the proper use of the Facebook for educational purposes.

\section{RESEARCH CONCLUSION, RECOMMENDATIONS AND FUTURE IMPLICATIONS}

The main purpose of this research was to learn more about the university students' expectations and viewpoints of utilizing Facebook as a supplementary course resource in one of the Jordanian higher education institutions. The participants provided a variety of expectations. The majority of these expectations were positive. These students were excited and accepted the idea of using social networking sites such as Facebook as a supplementary educational resource. They began to expand their vision of the educational consequences of Facebook. The expectations at the beginning of the semester match and agree with many of the students' perceptions after reflecting on 
their experience with this new educational tool. Despite the advantages of implementing Facebook as an additional learning resource, the students faced many challenges that lessened the usefulness of this page. The main obstacles were: the limited internet access for some students, the difficulty in managing courses' tasks, and the lack of computer skills. The study suggests that in order to overcome the mentioned obstacles adequate training about Facebook use is recommended for the students before offering this learning resource. Consequently, student will be more familiar and aware of the suitable use of this platform. Since some students do not have computers or internet access out of the university, it is recommended that the institutions of higher education allow students' access to Facebook as an educational tool. Related rules and regulations of the adequate use of social networking sites in the university settings are highly recommended to guide students to view Facebook use from a further angle. In this regard, future studies about the netiquette of using social networking sites in educational settings are highly recommended.

\section{REFERENCES}

[1] Arouri, Y. (2013). Negotiating the dimensions of the digital divide: A phenomenological study of Jordanian pre-service teachers' experiences with information and communication technology (ICT) access. Unpublished PhD Thesis, New Mexico State University, Las Cruces, New Mexico State.

[2] Astin, A. W. (1999). Student involvement: A developmental theory for higher education. Journal of College Student Development, 40, 518-529.

[3] Aydin, S. (2012). A review of research on Facebook as an educational environment. Educational Technology Research and Development, 60(6), 1093-1106. http://dx.doi.org/10.1007/s11423-0129260-7

[4] Boyd, D., \& Ellison, N. B. (2008). Social network sites: Definition, history, and scholarship. Journal of Computer-Mediated Communication, 13(1), 210-230. http://dx.doi.org/10.1111/j.10836101.2007.00393.x

[5] Cain, J. (2008). Online social networking issues within academia and pharmacy education. American Journal of Pharmaceutical Education, 72(1), 1-7. http://dx.doi.org/10.5688/aj720110

[6] Carlson, N. (2010). At last: The full story of how Facebook was founded. Retrieved on September 7, 2014 from: http://www.businessinsider.com/how-facebook-was-founded2010-3/we-can-talk-about-that-after-i-get-all-the-basicfunctionality-up-tomorrow-night-1

[7] Chen, P. S. D., Lambert, A. D., \& Guidry, K. R. (2010). Engaging online learners: The impacts of Web-based learning technology on college student engagement. Computers \& Education, 54, 1222 1232. http://dx.doi.org/10.1016/j.compedu.2009.11.008

[8] Creswell, J. (2007). Qualitative inquiry and research design: Choosing among five approaches. Thousand Oaks, CA: Sag.

[9] Crews, T. B., \& Stitt-Gohdes, W. L. (2012). Incorporating Facebook and Twitter in a Service-learning project in a business communication course. Business Communication Quarterly, 75(1), 7679. http://dx.doi.org/10.1177/1080569911431881

[10] eBizMBA (2014). The most popular social networking sites: September 2014. Retrieved on September 7, 2014 from: http://www.ebizmba.com/articles/social-networking-websites

[11] Facebook (2014). Facebook reports fourth quarter and full year 2013 results. Retrieved on September 7, 2014 from: http://investor.fb.com/releasedetail.cfm?ReleaseID $=821954$

[12] Hanson, T. L., Drumheller, K., Mallard, J. K., McKee, C., \& Schlegel, P. (2011). Cell phones, text messaging, and Facebook: Competing time demands of today's college students. College Teaching, 59(1), 23-30. http://dx.doi.org/10.1080/87567555. 2010.489078

[13] Irwin, C., Desbrow, L., \& Leveritt, M. (2012). Students' perceptions of using "Facebook" as an interactive learning resource at
University. Australasian Journal of Educational Technology, 28(7), 1221-1232.

[14] Ivala, E. E., \& Gachago, D. D. (2012). Social media for enhancing student engagement: The use of Facebook and Blogs at a University of Technology. South African Journal of Higher Education, 26(1), 152-167.

[15] Jarar, L. (2011). Participating in Facebook and its relationship to the trends of Jordanian university students towards family relations. Unpublished MA Thesis, Faculty of Information, University of the Middle East, Oman.

[16] Jenny, W., Chun-Fu C. L., Wei-Chieh W. Y., \& Emily, W. (2013). Meaningful engagement in Facebook learning environments: Merging social and academic lives. Turkish Online Journal of Distance Education (TOJDE), 14(1), 302-322.

[17] Junco, R. (2011). The relationship between frequency of Facebook use, participation in Facebook activities, and student engagement. Computers \& Education, 58, 162-171. http://dx.doi.org/10.1016/ j.compedu.2011.08.004

[18] Khadr, N. (2009). The psychological and social effects of the use of Egyptian youth to social networking sites: A study on the Facebook site. Paper presented at Family, Media, and the Era challenges Conference, the Faculty of Information: University of Cairo. February $15-17,2009$.

[19] Lincoln, Y., \& Guba, E. (1985). Naturalistic inquiry. Beverly Hills: SAGE Publication.

[20] McCarthy, J. (2010). Blended learning environments: Using social networking sites to enhance the first year experience. Australasian Journal of Educational Technology, 26(6), 729-740.

[21] Miller, S. T. (2013). Increasing student participation in online group discussions via Facebook. Astronomy Education Review, 12(1), 010103-1010103-10.

[22] Oradini, F. \& Saunders, G. (2008). The use of social networking by students and staff in higher education. Paper presented at the iLearning Forum, Paris. Retrieved on September 7, 2014 from: http://www.eifel.org/publications/proceedings/ilf08/contributions/i mproving-quality-of-learning-withtechnologies/Oradini_Saunders. pdf

[23] Pempek, T. A., Yermolayeva, Y. A., \& Calvert, S. L. (2009). College students' social networking experiences. Journal of Applied Developmental Psychology, 30(3), 227-238. http://dx.doi.org/10.1016/j.appdev.2008.12.010

[24] Pimmer, C., Linxen, S., \& Grohbiel, U. (2012). Facebook as a learning tool? A case study on the appropriation of social network sites from mobile phones in developing countries. British Journal $\begin{array}{lll}\text { of } & \text { Educational Technology, 43(5), }\end{array}$ http://dx.doi.org/10.1111/j.1467-8535.2012.01351.x

[25] Rambe, P. (2012). Critical discourse analysis of collaborative engagement in "Facebook" postings. Australasian Journal of Educational Technology, 28(2), 295-314.

[26] Roberts, J. \& McNeese, M. N. (2010). Student involvement / engagement in higher education based on student origin. Research in Higher Education Journal, 7(1), 1-11.

[27] Ryan, S. D., Magro, M. J., \& Sharp, J. H. (2011). Exploring educational and cultural adaptation through social networking sites. Journal of Information Technology Education, 10IIP.

[28] Selwyn, N. (2011). Web 2.0 applications as alternative environments for informal learning: A critical review. Proceedings of the Alternative Learning Environments in Practice: Using ICT to Change Impact and Outcomes, London, UK, 1-10.

[29] Shaltry, C., Henriksen, D., Wu, M., \& Dickson, W. (2013). Situated learning with online portfolios, classroom websites and Facebook. Techtrends: Linking Research and Practice to Improve Learning, 57(3), 20-25. http://dx.doi.org/10.1007/s11528-013$\underline{0658-9}$

[30] Shih, R. (2011). Can web 2.0 technology assist college students in learning English writing? Integrating "Facebook" and peer assessment with blended learning. Australasian Journal of Educational Technology, 27(5), 829-845.

[31] Shih, R. (2013). Effect of using Facebook to assist English for business communication course instruction. Turkish Online Journal of Educational Technology - TOJET, 12(1), 52-59.

[32] Singh, L. (2013). Guided assessment or open discourse: A comparative analysis of students interaction on Facebook 
PAPER

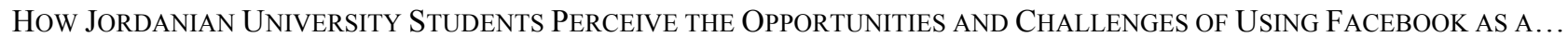

groups. Turkish Online Journal of Distance Education, 14(1), 3543.

[33] socialbakers (2014). Facebook overview statistics. Retrieved on September 7, 2014 from: http://www.socialbakers.com/facebookoverview-statistics/

[34] Souleles, N. (2012). Perceptions of undergraduate graphic design students on the educational potential of Facebook. Research in Learning Technology, 20(3), 241-252.

[35] Taylor, L. \& Parsons, J. (2011). Improving student engagement. Current Issues in Education, 14(1). Retrieved on September 7, 2014 from: http://cie.asu.edu/

[36] Vivian, R. (2011) 'University students' informal learning practices using Facebook: Help or hindrance? Communications in Computer and Information Science, 177, 254-267. http://dx.doi.org/10.1007/978-3-642-22383-9_21

[37] Wong, K., Kwan, R., Leung, K., \& Wang, F. (2014). Facebook's potential for personal, social, academic and career development for higher education students. Int. J. of Innovation and Learning, 16(2), 203 - 220. http://dx.doi.org/10.1504/IJIL.2014.064367

[38] Zepke, N., Leach, L., \& Butler, P. (2010). Student engagement: What is it and what influences it? Wellington: Teaching and Learning Research Initiative. Retrieved on September 7, 2014 from: http://www.tlri.org.nz/sites/default/files/projects/9261Introduction.pdf

\section{AUTHOR}

Y.M. Arouri is The Head Department of Curriculum and Instruction at Tafila Technical University, Jordan. Email: arouri@tt.edu.jo

Submitted 19 November 2014. Published as resubmitted by the author 21 February 2015. 